LETTERS

If you have a burning desire to respond to a paper published in Sex Transm Inf, why not make use of our "rapid response" option?

Log on to our website (www.sex transinf.com), find the paper that interests you, click on "full text" and send your response by email by clicking on "eletters submit a response".

Providing it isn't libellous or obscene, it will be posted within seven days. You can retrieve it by clicking on "read eletters" on our homepage.

The editors will decide, as before, whether to also publish it in a future paper issue.

\section{Enhanced risk of HIV sexual transmission during structured treatment interruption}

We report a case of HIV transmission through sexual intercourse while the sexual partner underwent antiretroviral structured treatment interruption. We would like to underline that giving proper information about a higher contamination risk during structured treatment interruption is a critical issue. Moreover, we consider that it is the responsibility of a medical investigator and physician to deliver a clear message in order to reinforce prophylaxis indications for sexual intercourse during this period.

A patient was infected with HIV for 9 years when he started HAART. At this time, his CD4 count was $280 \times 10^{6} / 1$ and plasma viral load was $5.1 \log _{10} / \mathrm{ml}$. A first structured treatment interruption (2 months' duration) was proposed after 2 years, while plasma viral load was undetectable. He was asked to use preservatives strictly at this time. A peak of HIV replication was observed $\left(4.3 \log _{10} / \mathrm{ml}\right)$. Treatment was then reintroduced. One year later, he was still healthy (CD4 count $450 \times$ $10^{6} / 1$ and undetectable plasma viral load). $\mathrm{He}$ asked for a new structured treatment interruption. Plasma viral load reached $4.6 \log _{10} / \mathrm{ml}$ 2 months later.

This homosexual man had a regular HIV negative sexual partner for 2 years. His HIV serology was found to be negative 2 months before the second structured treatment interruption. This sexual partner experienced a short period of unexplained fever 2 months after his boyfriend's treatment was discontinued. He was found to be HIV positive 4 months after structured treatment interruption. He denied having had any sexual relationship with other sexual partners during this period, as well as any other risk factor for HIV transmission. Moreover, genetic sequencing of the viruses, which was performed in both patients at the same date, revealed minor mutations on the protease gene (L63P, A7IV, and V77I) in both patients without any mutation on reverse transcriptase, which is another point to suggest the virus transmission by our patient.

Our HIV infected patient told us that he practised safe sex systematically during the first years of HIV infection, but that it was less systematic when viral load became undetectable (around 20\% of unprotected sexual intercourse during the past 2 years with this partner). He practised safe sex during the first structured treatment interruption, but not during the second one. Both of them denied any record of sexually transmitted infection except HIV. They were found to be negative for hepatitis B and C and syphilis.

Structured treatment interruption is an attractive strategy currently in evaluation in HIV-1 infected patients after long term viral suppression. As far as we know, antiretroviral interruption does not reduce therapy efficacy once reinitiated, delaying the reduction of viral load. ${ }^{1}$ During the phase of drug interruption, plasma HIV RNA rebounds to detectable levels within days of stopping HAART (median increase $0.2 \mathrm{log} /$ day). ${ }^{2}$ HAART treatment decreases HIV RNA concentration in blood and is generally associated with a decrease of seminal HIV RNA. ${ }^{3}$ Moreover, an increase of HIV RNA in plasma is known to enhance the risk of transmission. ${ }^{4}$ Finally, we may assume that a sudden increase in HIV RNA in blood during structured treatment interruption may induce a viral rebound in semen.

Some key messages have to be taken into account. Firstly, the impact of sexual transmission during clinical trials assessing the benefit/risk ratio of structured treatment interruption has to be evaluated prospectively as a side effect of the strategy. Secondly, patients have to be informed that they are particularly at risk of HIV transmission during this period and that sexual relations have to be heavily protected when antiretroviral regimen is stopped. It is the responsibility of investigators involved in such trials to inform patients. Thirdly, in order to avoid complaints against physicians, we believe that patients must be informed of this very high risk period.

E Teicher, T Casagrande, D Vittecoq Unité des Maladies Infectieuses, Hôpital Paul Brousse, 94804 Villejuif, France

Correspondence to: Elina Teicher elina.teicher@pbr.ap-hop-paris.fr

\section{References}

1 Neumann A, Tubiana R, Calvez V, et al and the Comet Study Group. HIV-1 rebound during interruption of highly active antiretroviral therapy has no deleterious effect on reinitiated treatment. AIDS 1999;13:677-83

2 Harrigan R, Whaley M, Montaner J. Rate of HIV RNA rebound upon stopping antiretroviral therapy. AIDS 1999;13:F59-62.

3 Vernazza PL, Gilliam B, Flepp $M$, et al. Effect of antiviral treatment on the shedding of HIV-1 in semen. AIDS 1997;11:1249-54.

4 Pedraza MA, Del Romero J, Roldan F, et al. Heterosexual transmission of HIV-1 is associated with high plasma viral load levels and a positive viral isolation in the infected partner. J Aquir Immune Defic Syndr 1999;21:120-5.

Accepted for publication 30 September 2002

\section{Chaperoning in genitourinary medicine clinics}

In 1996 the General Medical Council recommended, where possible, offering chaperones to patients during intimate examinations. This advice was incorporated into a report from a Royal College of Obstetricians and Gynaecologists working party. ${ }^{1}$ Subsequently, Torrance et al performed a postal survey of practice in 175 genitourinary medicine (GUM) clinics in the United Kingdom. ${ }^{2}$ This study also concluded that chaperones should be offered to patients more widely during genital examinations in genitourinary medicine (GUM) clinics. ${ }^{2}$ In contrast, other studies have shown that male patients are comfortable with genital examinations being performed by doctors of either sex, ${ }^{3}$ and that it is not necessary to provide a chaperone when male patients are examined by a male doctor. ${ }^{4}$

We carried out a postal survey of the use of chaperones in 31 GUM clinics in the North Thames Region in order to assess current practice. Responses were received from 20 centres $(64.5 \%)$. Only two ( $10 \%)$ clinics had a written clinic policy and only one (5\%) had carried out a patient survey on views about the provision of chaperones. None of the clinics had carried out a staff (nurses and doctors) survey of their views about chaperoning.

We identified two interesting observations (table 1). Firstly, there was a significant difference in provision of chaperones for female patients, depending on whether the person carrying out the examination was a female doctor $(12 / 20)$ or a female nurse $(1 / 20)$; Yates's corrected $\chi^{2}$ test $=11.40,1 \mathrm{df}$, $\mathrm{p}<0.001$. Secondly, there was a difference in provision of chaperones for female patients examined by female doctors (12/20) compared with male patients examined by male doctors (2/20); Yates's corrected $\chi^{2}$ test $=8.90$, $1 \mathrm{df}, \mathrm{p}<0.003$ (table 1 ).

In addition, it was noted that in 18 clinics not offering routine availability of chaperones for male patients being examined by a male

Table 1 Results of a postal survey of practice in 20 GUM clinics in the North Thames Region

\begin{tabular}{lrr}
\hline & \multicolumn{2}{l}{$\begin{array}{l}\text { Chaperone } \\
\text { offered }\end{array}$} \\
\cline { 2 - 3 } & Yes & No \\
\hline Female patient: & 12 & 8 \\
Female doctor & 1 & 19 \\
Female nurse & 20 & 0 \\
Male doctor & 12 & 0 \\
Male nurse ${ }^{*}$ & & \\
Male patient: & 4 & 15 \\
Female doctor $\ddagger$ & 3 & 15 \\
Female nurse§ & 2 & 18 \\
Male doctor & 1 & 18 \\
Male nurse $\dagger$ & 18 \\
\hline
\end{tabular}

* Seven clinics do not allow this interaction; †one clinic does not have male nurses; łone clinic does not allow the interaction; §łtwo clinics do not allow this interaction. 
doctor or nurse, a chaperone would be offered in six clinics (33\%) for cases of sexual assault, or for colposcopy. A chaperone would also be offered for the procedure of prostatic massage in five clinics (28\%). Several clinics reported that they were more likely to offer chaperones to those patients with a past history of aggressive behaviour towards staff or to those with psychiatric problems.

Our study does not inform the discussion as to who should act as chaperone in GUM clinics. Previous studies in general practice have suggested that adolescent females prefer a female relative to be present during a genital examination. In the context of the GUM clinic, perhaps the specialist nurse or healthcare assistant is the ideal person-as in addition to reassuring the patient, they may aid the examiner and safeguard both patient and healthcare worker against allegations of inappropriate behaviour. In some small clinics this may be an impossible target to meet. However, the time and cost of resolving allegations against healthcare workers must be balanced against the costs of employing appropriate staff.

R Miller, K Jones

Department of Sexually Transmitted Diseases, Royal Free and University College Medical School, University College London, Mortimer Market Centre, London WCIE 6AU, UK

D Daniels

West Middlesex Hospital Sexual Health Clinic, West Middlesex University Hospital, Isleworth

TW7 6AF, UK

G Forster

Ambrose King Centre, The Royal London Hospital, London El 1BB, UK

M G Brook

Patrick Clements Clinic, Central Middlesex Hospital, London NW10 7NS, UK

Correspondence to: Rob Miller rmiller@gum.ucl.ac.uk

\section{References:}

1 Royal College of Obstetricians and Gynaecologists. Intimate examinations: report of a working party. London: RCOG, 1997.

2 Torrance CJ, Das R, Allison MC. Use of

chaperones in clinics for genitourinary medicine: survey of consultants. BM 1999:319:159-60

3 Fisk P, Barmi K, Morgan C. Chaperoning male patients. Sex Transm Infect 2000;76:495.

4 O'Mahoney C. Chaperoning male patients. Sex Trans Infect 2000;77:225-6

5 Penn MA, Bourguet CC. Patients' attitudes regarding chaperones during physical examination. J Fam Pract 1992;35:639-43

Accepted for publication 30 September 2002

\section{Cytokine profiles in HIV seropositive patients with tuberculous meningitis}

The immunological response in pulmonary and pleural tuberculosis has been extensively studied. However, the response in tuberculous meningitis has not been well documented. ${ }^{1}$ In pulmonary disease, exposure to tuberculous antigens results in a $\mathrm{T}$ cell and natural killer cellular response, elaborating various cytokines, mainly of T helper type 1 (Thl) origin. Stimulated macrophages elaborate tumour necrosis factor (TNF) $\alpha$, interleukin (IL) 12 and IL 1, promoting further recruitment and activation of macrophages and lymphocytes.

TNF $\alpha$ correlates with disease severity and may contribute to tissue necrosis; however, $\mathrm{TNF} \alpha$ has also contributed to survival in mouse studies. ${ }^{2}$ Transforming growth factor $\beta$ (Th3 cytokine) suppresses macrophage activation. IL 2 may be beneficial in promoting an immune response in HIV seropositive patients. Th1 and Th2 cytokine responses have been observed in cerebrospinal fluid (CSF) of HIV seronegative patients with tuberculous meningitis. ${ }^{34}$. Whether the response is similar in HIV seropositive patients with tuberculous meningitis is unknown.

We studied the cytokine response and its correlation with disease severity in HIV seropositive and HIV seronegative patients with tuberculous meningitis.

Tuberculous meningitis was diagnosed on clinical and CSF examination after exclusion of viral, acute bacterial, and other causes of aseptic meningitis. Disease severity was assessed according to the Medical Research Council stages 1 to 3 . HIV ELISA was done on all patients. CSF samples were subjected to microscopy, culture, protein and glucose analysis, Venereal Disease Research Laboratory test, fluorescent treponemal antibody analysis, cryptococcal antigen analysis, viral studies, cysticercus ELISA, CD4 counts, and determination of concentrations of adenosine deaminase (ADA), CSF IgG, and albumin.

For cytokine assays, CSF was centrifuged at $3000 \mathrm{~g}$, and supernatant was aliquoted and stored at $-70^{\circ} \mathrm{C}$. TNF $\alpha$, interferon (IFN) $\gamma$, and IL 10 concentrations were measured by ELISA kits (Genzyme Diagnostics, Cambridge, Massachusetts, USA) with detection limits of $3 \mathrm{pg} / \mathrm{ml}, 3 \mathrm{pg} / \mathrm{ml}$, and $5 \mathrm{pg} / \mathrm{ml}$, respectively.

Data were summarised as medians and ranges. Non-parametric Wilcoxon rank sum tests were used to compare HIV seropositive groups with HIV seronegative groups, tuberculous meningitis severity groups, and groups derived according to the blood brain barrier index for cytokine concentrations. Spearman's rank correlation was used to derive correlations of cytokine concentration, ADA concentrations, and $\mathrm{CD} 4$ counts in $\mathrm{CSF}$.

There were 27 patients: 18 (67\%) women and 9 (33\%) men. Seventeen were HIV seropositive and $10 \mathrm{HIV}$ seronegative. The average interval between onset of symptoms and the first clinical assessment was 17 days (range 5-90 days) in 18 patients where this was recorded. The mean (SD) age was 26.8 (11.6) years. There was one patient aged 10 and one aged 60 , and the rest were between 25 and 40 . The cytokine concentrations were not analysed according to age, as this would make the categories too small and of little value. The
IgG index was calculated for 23 patients. There was no significant difference between the HIV seropositive and HIV seronegative groups for $\mathrm{ADA}(\mathrm{p}=0.4)$ and $\mathrm{CD} 4$ counts $(\mathrm{p}=0.19)$ in CSF and cytokine concentrations (table 1).

Ten patients (37\%) were classified as having grade 1 tuberculous meningitis. Sixteen $(59 \%)$ had grade 2 and one (4\%) grade 3 , which for analysis was considered to be grade 2 . Table 1 summarises the cytokine concentrations for patients in stages 1 and 2 .

Patients with stage 2 disease had significantly stronger Thl responses. There was no difference in the IL 10 concentrations. The two patients with stage 2 disease who died had very high IFN $\gamma$ concentrations, both greater than $2048 \mathrm{pg} / \mathrm{ml}$.

IL 10 concentrations were moderately positively correlated with IFN $\gamma$ concentrations $(r=0.53)$. The correlation coefficients were -0.18 for IFN $\gamma,-0.33$ for TNF $\alpha$, and -0.34 for IL 10. Correlation coefficients between ADA and cytokine concentrations were 0.34 for IFN $\gamma, 0.47$ for TNF $\alpha$, and 0.22 for IL 10. Cytokine concentrations correlated poorly with CD4 counts in CSF.

It is postulated that in HIV infection a predominant Th2 response accounts for extrapulmonary disease. ${ }^{5}$ This study does not favour a predominance of either Thl or Th2 in the CSF. It is possible that a Th0 response, which is a non-differentiated response seen early on in immune activation, was seen in our patients, as they were examined untreated and relatively early in the disease. Other investigators have also documented this phenomenon. ${ }^{3}$ The positive correlation between IFN $\gamma$ and IL 10 suggests that these were produced concurrently. This may reflect a control mechanism regulating Thl and Th2 responses.

There was no difference in cytokine and ADA concentrations and CD4 counts between HIV seropositive and HIV seronegative patients. It is known that the clinical response to antituberculous treatment in both groups is similar. ${ }^{5}$ Perhaps this similarity correlates with similar immune responses in both groups. The size of each group is small and a type 1 statistical error has to be considered. Further studies to confirm our findings would be of value.

The significantly greater TNF $\alpha$ and IFN $\gamma$ concentrations in the severe group of tuberculous meningitis is confirmed by other studies ${ }^{6}$ and suggests that disease severity results mainly from the immune response rather than the organism itself.

The lack of correlation between CD4 and cytokine concentrations may be explained by the fact that there are other sources of cytokines in the CSF, namely macrophages and natural killer cells. Concentrations of ADA, which are derived from lymphocytes, are consistent with other reports, where they were correlated with cytokine concentrations.

There was no correlation between the IgG index and cytokine concentrations, suggesting that the blood brain barrier did not

Table 1 Differences between HIV seropositive and HIV seronegative groups and tuberculous meningitis severity

\begin{tabular}{|c|c|c|c|c|c|c|c|c|c|c|}
\hline \multirow[b]{2}{*}{ Cytokine } & \multicolumn{2}{|c|}{ HIV positive } & \multicolumn{2}{|c|}{ HIV negative } & \multirow[b]{2}{*}{$p$ Value } & \multicolumn{2}{|l|}{ Stage 1} & \multicolumn{2}{|l|}{ Stage 2} & \multirow[b]{2}{*}{$\mathrm{p}$ Value } \\
\hline & Median & Range & Median & Range & & Median & Range & Median & Range & \\
\hline IFN $\gamma(\mathrm{pg} / \mathrm{ml})$ & 569.9 & $16.0-2048$ & 890.6 & $0-2048$ & 0.9 & 184.5 & $0-1771.0$ & 1000.0 & $16.0-2048$ & 0.03 \\
\hline TNF $\alpha(\mathrm{pg} / \mathrm{ml})$ & 1.6 & $0-67.5$ & 9.8 & $0-309.3$ & 0.11 & 0.65 & $0-19.2$ & 9.8 & $0-309.3$ & 0.008 \\
\hline IL 10 (pg/ml) & 24.6 & $0-127.9$ & 17.3 & $0-296.3$ & 0.9 & 3.68 & $0-53.0$ & 27.4 & $0-296.4$ & 0.97 \\
\hline
\end{tabular}

IFN, interferon; II, interleukin; TNF, tumour necrosis factor. 
significantly influence concentrations. Unfortunately, corresponding serum concentrations were not available. This would have been valuable. This is the first study correlating CSF cytokine responses to severity of tuberculous meningitis and comparing HIV positive with HIV negative groups. Further studies should be done to confirm these findings, perhaps to define their relevance to complications and to explore the possibility of IL 2 treatment in HIV positive patients.

Reproduced in full with permission from

J Neurol Neurosurg Psychiatry 2002;73:598-599

\section{Acknowledgements}

This study was sponsored by the Glaxo TB initiative.

VB Patel, Al Bhigiee, PLA Bil

Division of Neurology, Nelson R Mandela School of Medicine, University of Natal, Durban, South

CA Connolly

Biostatistics, Medical Research Council, Durban, South Africa

Correspondence to: Dr VB Patel, Department of Neurology, Ward A3, Wentworth Hospital, Private Bag Jacobs, Durban 4026, South Africa; patelv@nu.ac.zo

\section{References}

1 Barnes PF, Modlen RL, Milner J. T-cell responses and cytokines in tuberculosis, pathogenesis, protection and control. Washington: BR Bloom American Press, 1994:417-35.

2 Flynn JL, Goldstein MM, Chan J, et al. Tumor necrosis factor-alpha is required in the protective immune response against Mycobacterium tuberculosis in mice. Immunity 1995;2:561-72.

3 Donald PR, Schoeman JF, Beyers N, et al. Concentration of IFN- $\gamma$, TNF- $\alpha$ and ILI- $\beta$ in CSF of children treated for TBM. Clin Infect Dis 1995;21:924-9.

4 Havlir DV, Barnes PF. Tuberculosis in patients with human immunodeficiency virus infection. N Engl J Med 1999:340:367-73.

5 Berger JR. Tuberculous meningitis. Curr Opin Neurol Neurosurg 1994;7:191-200.

6 Thwaites G, Chau TTH, Mai NTH, et al.

Tuberculous meningitis. J Neurol Neurosurg

Psychiatry 2000;68:289-99.

\section{Hepatitis C testing in HIV infected patients}

Numerous seroprevalence studies have shown a high rate of co-infection with hepatitis $C$ among HIV-l infected patients, ranging from $98 \%$ in haemophiliacs, $80 \%$ among injecting drug users, to $3-15 \%$ in homosexual/bisexual men. ${ }^{1}$ Although it is estimated that there are 200 000-400 000 people infected with hepatitis C (HCV) in the United Kingdom, ${ }^{2}$ the number of coinfected individuals is unknown. Data have shown that HIV increases the rate of HCV progression, ${ }^{1}$ and there is also some evidence suggesting that HCV worsens HIV progression, although this is more controversial.

There is a growing recognition of the significant impact of co-infection on the management of HIV disease. Hepatitis morbidity and mortality among coinfected patients has increased fivefold in recent years. Furthermore the presence of HCV increases the frequency of hepatotoxicity with antiretroviral therapy, and may also impact on the choice of antiretroviral drug, with avoidance of drugs that are potentially hepatotoxic such as ritonavir and nevirapine. ${ }^{4}$ Most importantly there is now effective treatment available for the management of HCV infection. ${ }^{2}$
Recent preliminary data suggest in HIV-HCV co-infected patients superior virological response in those receiving PEG-interferon with ribavirin compared to standard interferon with ribavirin. ${ }^{5}$ Finally, management of the HIV-HCV co-infected patients involves other interventions such as vaccination for other viral hepatitis $\mathrm{A}$ and $\mathrm{B}$, and reducing alcohol intake.

These findings all highlight the importance of identifying those HIV infected patients who are co-infected with HCV. However, a recen survey at Kings' College Hospital in March 2002 revealed that only $63 \%$ of a cohort of 850 current HIV infected attendees had been tested for HCV. The majority of those not ye tested for HCV were patients who had presented before the routine introduction of HCV testing in 1999. Similar findings have been reported from other European centres. In a French cohort of 4017 HIV infected patients only 2589 (64\%) were tested for $\mathrm{HCV}^{6}$ Although a substantial number of these patients have stored samples available on which retrospective HCV testing could be performed, the current guidance from Royal College of Physicians working group is that consent must be obtained before testing.

Current guidelines from the United States now recommends HCV testing for all HIV infected patients. ${ }^{8}$ Antibody based screening assays for HCV infection have evolved over the past decade and currently the most widely are third generation ELISA assays (Ortho). ${ }^{2}$ Confirmation of positive results by recombinan immunoblot assays (Chiron RIBA, others) is still recommended as a proportion of positive tests may represent false positive results. Qualitative and quantitative PCR (polymerase chain reaction) tests that detect the presence of HCV RNA and have sensitivity in the range of 50-1000 equivalents per $\mathrm{ml}$ are now also available. ${ }^{2}$ We undertook a recent informal survey of 10 UK teaching hospitals, which showed differences in HCV testing policies. Seven clinical sites use serological testing for screening and confirm all initially positive results with a second serological assay, and then confirm positive results with a qualitative PCR test. Three sites use qualitative PCR testing for those with an initial positive serological test. For those with a negative PCR further confirmatory antibody assay are done at two sites and one site requests repeat PCR testing at 6 and 12 months.

What is the role of PCR testing in COinfection? At least $4-7 \%$ of HIV-HCV coinfected patients have no detectable antibodies in the presence of HCV viraemia ${ }^{9}$ as they fail to produce antibodies or have low titres (can't be detected or give equivocal or indeterminate) or loss of detectable antibodies from serum despite persistent viraemia in immunosuppressed patients..$^{10}$ Therefore, additional testing with PCR is often indicated. The guidelines recommend ${ }^{2}$ that all patients with positive HCV antibody tests and those patients thought to be at risk of HCV infection despite negative or indeterminate serological tests should undergo qualitative PCR testing of serum. A positive result confirms curren viraemia whereas a negative test suggests non-viraemic infection. Patients with a a positive ELISA but negative PCR should be tested with recombinant immunoblot assay to confirm antibody status.

In conclusion, we recommend that centres caring for HIV infected patients should develop clear policies and strategies for ensuring all their new and existing HIV infected patients have undergone testing for HCV.
A H Mohsen, P Easterbrook Department of HIV/GU Medicine, The Guys', Kings, and St Thomas's School of Medicine, Denmark HII, London SE5 9RJ, UK

Correspondence to: Dr Mohsen; abdul.mohsen@kcl.ac.uk

\section{References}

1 Mohsen A H, Easterbrook P, Taylor C, et al. Hepatitis $C$ and HIV-1 Infection. Gut 2002;51:601-8

2 Bootha J C L, O'Grady J, Neuberger J. Clinical guidelines on the management of hepatitis C, on behalf of the Royal College of Physicians of London and the British Society of Gastroenterology. Gut 2002;49/Suppl I):11-21

3 Greub G, Ledergerber B, Battegay M, et al, Clinical progression, survival, and immune recovery during antiretroviral therapy in patients with HIV-1 and hepatitis $C$ virus coinfection: the Swiss HIV Cohort Study. Lancet 2000;356:1800-5.

4 Soriano V, Sulkowski M, Bergin C, et al. Care of patients with chronic hepatitis $C$ and HIV co-infection: recommendations from the HIV-HCV International Panel. AIDS 2002;16:813-28. (Review.)

5 Chung R, Andersen J, Alston B, et al. A randomized, controlled trial of pegylated interferon alpha-2a with ribavirin vs Interferon alpha-2a with ribavirin for the treatment of chronic HCV in HIV co-infection. 9th CROI 2002 (abstract LB-15), http:// www. retroconference.org/2002/Abstract/ 14102.htm

6 Benhamou Y, Di Martino V, Bochet M, et al. Factors affecting liver fibrosis in human immunodeficiency virus-and hepatitis $C$ virus-coinfected patients: impact of protease inhibitor therapy. Hepatology 2001;34:283-7.

7 Medical Research Council. Human tissue and biological samples for use in research. www.mrc.ac.uk, April 2001

82001 USPHS/IDSA Guidelines for the Prevention of Opportunistic Infections in Persons Infected with Human Immunodeficiency Virus. www.ama-assn.org/ special/hiv.

9 Bonacini $\mathbf{M}$, Lin HJ, Hollinger FB. Effect of coexisting HIV-1 infection on the diagnosis and evaluation of hepatitis $C$ virus. J AIDS. 2001;26:340-4.

10 Chamot E, Hirchel B, Wintsch J, et al. Loss of antibodies against hepatitis $C$ virus in HIV-seropositive intravenous drug users. AIDS 1990:4:1275-7.

Accepted for publication 10 October 2002

First, do not harm: also an issue in NAA assay diagnostics for chlamydial infection

In his update on Chlamydia trachomatis diagnostics, ${ }^{1}$ Chernesky emphasises that nucleic acid amplification (NAA) assays can be useful for screening purposes, because of their increased sensitivity and the possibility of non-invasive sample collection. Since the introduction of these assays, many screening interventions have been undertaken and evaluated mostly in an optimal research context. However, a number of problems can be expected if these diagnostics are implemented in large scale routine clinical practice or in community screening programmes.

Firstly, multiple testing sites may be needed for accurate results, ${ }^{1}$ but cannot be realised for reasons of cost and inconvenience.

Secondly, the positive predictive value of a test is low in low prevalence populations. To avoid false positive diagnoses in these situations repeat testing of the sample, preferably by a different technique, is highly recommended. However, in clinical practice a single 
positive result is often considered to indicate that a patient is infected. ${ }^{2}$

Thirdly, reproducibility problems do occur and are varying in time, ${ }^{3}$ and confirmatory testing is required when test results are intermediate or near the cut-off value. A low positive test result that is not caused by the presence of amplification inhibitors points to a low number of target organisms in the sample. Repeat testing is then a matter of statistical chance of the second portion of the sample containing detectable numbers of target organisms. Such results should be transmitted to the clinician accompanied by interpretative comments.

Fourthly, diagnostic accuracy may be affected by contamination of the specimen during laboratory processing

Fifthly, it is not clear whether detection of a very small amount of chlamydial DNA always reflects clinically significant infection: NAA assays might identify residual DNA from a cleared or treated infection, DNA of nonviable organisms, or DNA of levels of pathogens which are too low to be infectious. ${ }^{45}$

For this reasons it is likely that in routine practice a number of results will be interpreted as positive in patients who are not truly infected.

However, the impact of a chlamydia diagnosis on people's lives is considerable, ${ }^{6}$ and can include stigmatisation, anxiety about reproductive health, and potential partner discord. Pre-test and post-test counselling has been shown to be labour intensive for healthcare providers too, since most infections in asymptomatic patients will be unexpected.

To overcome these problems, rigid diagnostic protocols must be developed before introducing any screening programme. Not only should infected people be identified but false positive diagnoses should be avoided. Laboratories should participate in quality control programmes, and test runs should include multiple controls. Healthcare providers should be offered agreed standards to which they can manage the different aspects of screening and counselling for chlamydial infection.

V Verhoeven, M leven, A Meheus, D Avonts, $\mathrm{H}$ Goossens University of Antwerp, Universiteitsplein 1, Wilrijk 2610, Belgium

Correspondence to: Veronique Verhoeven verover@via.va.ac.b

\section{References}

1 Chernesky MA. Chlamydia trachomatis diagnostics. Sex Transm Infect 2002;78:232-4.

2 Garrow SC, Smith DW, Harnett GB. The diagnosis of chlamydia, gonorrhea, and trichomonas infections by self obtained low vaginal swabs, in remote northern Australian clinical practice. Sex Transm Infect 2002;78:278-81.

3 Mallinson H, Hopwood J, Mutton K. Resolution of the recent performance problem of Abbott LCx Chlamydia trachomatis assay. Issues of repeat testing for confirmation of chlamydial infection. Sex Transm Infect 2002;78: 225-6

4 Louie $M$, Louie L, Simor AE. The role of DNA amplification technology in the diagnosis of infectious diseases. CMA 2000; 163:301-9.

5 Turner CF, Rogers SM, Miller HG, et al. Untreated gonococcal and chlamydia infection in a probability sample of adults. JAMA 2002;287:726-33.

6 Duncan B, Hart G, Scoular A, et al. Qualitative analysis of psychosocial impact of diagnosis of Chlamydia trachomatis: implications for screening. BM 2001;322:195-9.

Accepted for publication 17 October 2002

\section{Geographical focusing: an intervention to address increased risk for sexually transmitted diseases during repatriation and resettlement in post-war Mozambique}

Countries in the early post-war phase face population movements contributing to in creased vulnerability for sexually transmitted diseases (STD) and HIV. Mozambique chose geographically focused interventions to control STD spread in the first post-war years.

Mozambique was one of the poorest countries in the world in 1993 with per capita GNP of US\$63 and life expectancy of 48 years.

Seventeen years of civil war and economic crisis destabilised the country causing massive population movements towards urban areas and neighbouring countries. Between 1992 and 1995, an estimated 1.7 million refugees from Malawi, Zimbabwe, Tanzania, Zambia, and Swaziland returned, soldiers were demobilised, and internally displaced people resettled. ${ }^{2}$ The war destroyed the health infrastructure, especially in rural areas, precluding provision of STD services and effective primary health care (PHC). ${ }^{3}$

Vulnerable groups and populations of the areas through which the refugees were returning, were considered particularly vulnerable to the risk of STD/HIV ${ }^{4}$

The National STD/AIDS Control Programme, supported by the European Commission, decided to focus STD/HIV interventions at the PHC level in the areas most affected by population movements.

Four studies carried out between 1987-92 showed HIV seroprevalence rates of $3.2 \%$ $4.6 \%$ in displaced populations, higher than the $1.2 \%$ of the general population.

Very high STD prevalence rates $(51 \%)$ were demonstrated in pregnant women attending PHC services for antenatal care. Displaced populations showed lower awareness of condoms than the general population. ${ }^{6}$

Fifteen districts in five provinces were selected on the basis of existing population health facilities and projected influx of people. ${ }^{2}$ PHC services were strengthened overcoming the existing shortages of staff, drugs, and materials. Clinical, laboratory, and health education skills of over 100 PHC workers in these priority districts were upgraded through training. Drugs for STD treatment, condoms, and educational materials were delivered. An existing popular health education initiative using theatre groups expanded, reaching over 100000 people in local languages.

Difficulties encountered were mostly related to the destabilisation due to the war, such as transport problems, demotivation and relocations of health staff, parallel drug and treatment markets, and poor condom availability. Nevertheless, significan progress was noted. One major achievement was the increase in STD patient attendance, quadrupling in one province and doubling or tripling in others. The number of contacts reached also increased significantly: in $1992,4.5 \%$ of STD patients were contacts, in 1993 9\%, and in 1994 20.8\%. Another achievement was increased condom distribution, from 2.5 million in 1993 to 5 million in 1994.
Geographical focusing of interventions in early post-war Mozambique showed significant impact on STD attendance, proving the feasibility of introducing STD care in difficult circumstances. Strengthening 15 districts provided the basis for improvement of the STD programme in other areas and enhanced general functioning of PHC centres in the initial priority districts. Improved supervision, in turn improving clinical, laboratory, and educational activities, was subsequently expanded to other districts. The use of syndromic management protocols contributed positively to STD management throughout the country.

Focusing interventions in areas with especially vulnerable populations, combined with an integrated approach to STD/HIV control, may have contributed to the control of the spread of STD and HIV in early post-war Mozambique.

\section{Acknowledgements}

Grant: European Commission, DG VIII/8, contract No RPR-MOZ-003.

The authors would like to thank all those who contributed to this letter and especially Kathy Attawell for her assistance in editing this report and Professor Marleen Temmerman of Ghent University for her encouragement and assistance.

B De Hulsters

Former technical assistant European Commission, Mozambique

A Barreto, R Bastos, A Noya National STD and AIDS Control Programme, Mozambique

E Folgosa

National Reference Laboratory Microbiology, Faculty of Medicine, Eduardo Mondlane University, Mozambique

L Fransen

Health, AIDS and Population, DGDEV, European Commission, Belgium

Correspondence to: Dr Brigitte De Hulsters, International Centre for Reproductive Health, University Hospital, De Pintelaan 185 P3, B-9000 Gent, Belgium; bdhulsters@hotmail.com

\section{References}

1 World Bank. World development report Oxford: Oxford University Press, 1993.

2 United Nations High Commission for Refugees. Mozambique 1993/95 review: towards reintegration. Maputo, Mozambique: UNHCforR, 1995.

3 Bastos R, Folgosa E, Fransen L. Reproductive tract infections in Mozambique: a case study of integrated services. New York: Plenum Press, 1992.

4 Palha de Souza C, Noya A, Barreto A. Resettlement in post-war Mozambique: implications for STD/HIV control. Abstract no ThPE 134, VIII International Conference on AIDS in Africa, Marrakech, Morocco, 1993.

5 Vuylsteke B, Bastos R, Barreto J, et al. High prevalence of STD in a rural area in Mozambique. Genitourin Med 1993:69:427-30.

6 Noya A, Fernandes A. Inquerito de conhecimentos, attitudes e praticas sobre o SIDA em jovens, militares e deslocados de guerra nas provincias de Cabo Delgado e Nampula. Documento do gabinete de epidemiologia, DNS/Ministerio de Saude, 1990

Accepted for publication 20 September 2002 


\section{A novel research approach in sex on premises venues (SOPV): objective measure of sexual behaviour and low level intrusion to patrons}

Sex on premises venues (SOPV) are commercial venues where men who have sex with men (MSM) meet other MSM for casual, usually anonymous, sex. These venues are challenging environments for traditional methods of behavioural research-for example, interviews. An alternative research method adapted from a study with sex workers in Nicaragua may be used in SOPVs. ${ }^{12}$ This study counted the number of used condoms per client as a measure of "safe" sexual behaviour. A pilot study in two parts was conducted at a Melbourne SOPV to determine the feasibility of this approach. The merit of this method was dependent on the consistency of the ratio of used condoms per SOPV patron, and consequently the method's sensitivity to detect behaviour change.

Part 1 of this pilot aimed to establish a system of SOPV waste collection and condom counting. SOPV staff collected venue waste and research staff counted the number of condoms in the waste that were free from condom packaging. Part 2 piloted SOPV staf handing out anonymous, self complete questionnaires to patrons during the time periods when waste was being collected. The questionnaire only asked about anal sex and condom use during the participant's visit at the SOPV.

Part 1 operated on 16 Saturdays and Sundays during the day. An overall ratio of 0.8 condoms per patron was calculated $(95 \% \mathrm{CI}$ : 0.7 to 1.1$)$, and the ratio for each day ranged from 0.3 to 1.6. It was suspected that inconsistent collection of waste on Saturdays and Sundays contributed to the variability of the calculated condom to patron ratio each day. To have the same SOPV staff collecting waste each time and to avoid weekend functions at the SOPV, collection continued on the following nine Wednesday and Thursday evenings. For these evenings an overall ratio of 0.56 condoms per patron was calculated $(95 \%$ CI: 0.4 to 0.7$)$, and the ratio for each day ranged from 0.2 to 1.0

Part 2 of this pilot operated on Wednesday and Thursday evenings of the following 8 weeks. Approximately 180 patrons were given a questionnaire by SOPV staff, of which 76 $(\sim 40 \%)$ completed and returned the questionnaire (mean 43.8 (SD 13.3 years). Forty four participants reported engaging in protected anal sex during their visit to the SOPV (58\%, $95 \%$ CI: $47 \%$ to $69 \%$ ), with a mode of one episode of protected anal sex per visit. Using this proportion of $58 \%$, a ratio of 1.4 condoms per patron engaging in protected anal sex was recalculated for the Saturday and Sunday collections. For all Wednesday and Thursday collections (Part 1 and 2 ) the ratio was 0.9 .

The findings of this pilot study are inconclusive with respect to the value of this research method for behavioural study. Controlling for measurement and selection bias was difficult and resulted in a variable ratio of used condoms to patrons for each collection day. Research projects with more resources should look for greater control of bias, including encouragement of good communication with SOPV staff. However, this pilot study has demonstrated the potential of counting discarded condoms as a measure of safe sex behaviour in SOPVs. Counting condoms is an objective measure that doesn't rely on self reports of behaviour, and condom collection can be conducted with minimal intrusion to patrons visiting the SOPV.

N A Lister, A Smith, A Binger, C K Fairley The University of Melbourne, School of Population Health, 2nd Floor, 723 Swanston Street, Carlton 3053, Victoria, Australia

Correspondence to: Christopher K Fairley, cfairley@unimelb.edu.au

\section{References}

1 Gorter A Miranda E, Smith GD, et al. How many people actually use condoms? An investigation of motel clients in Managua. Soc Sci Med 1993;36:1645-7

2 Egger M, Pauw J, Lopatitzidis A, et al. Promotion of condom use in a high-risk setting in Nicaragua: a randomized controlled trial. lancet 2000:355:2101-5.

Accepted for publication 16 October 2002

\section{NOTICES}

\section{International Herpes Alliance and International Herpes Management Forum}

The International Herpes Alliance has introduced a website (www.herpesalliance.org) from which can be downloaded patient information leaflets. Its sister organisation the International Herpes Management Forum (website: www.IHMF.org) has launched new guidelines on the management of herpesvirus infections in pregnancy at the 9th International Congress on Infectious Disease (ICID) in Buenos Aires.

\section{Pan-American Health} Organization, regional office of the World Health Organization

A catalogue of publications is available online (www.paho.org). The monthly journal of
PAHO, the Pan American Journal of Public Health, is also available (subscriptions: pubsvc@tsp.sheridan.com).

\section{International Congress of the} Society of The Fetus as a Patient

1-4 May 2003, Gran Hotel Sitges, BarcelonaSitges, Spain

Further details: (fax: +34 93418 7832; email: bcn2003@iudexeus.uab.es).

\section{Australasian Sexual Health Conference: Tango down South-2003!}

4-7 June 2003, Christchurch Convention Centre, New Zealand

Further details: Dart Associates (tel: +02 9418 9396/97; email: dartconv@mpx.com.au; web site: http://www.acshp.org.au).

\section{CORRECTION}

We would like to apologise for an error that occurred in the paper by McGarrigle et al (Sex Transm Infect 2002;78:398-405). In table 2 under the heading "Name and custodian" the following affiliations should have appeared. Row one: London School of Hygiene and Tropical Medicine, National Centre for Social Research, and Royal Free \& University College Medical School. Row six: City University and Department of Primary Care and Population Sciences and Royal Free Centre for HIV Medicine, Royal Free \& University Medica College. Row seven: Study on HIV testing. Royal Free Hampstead NHS Trust Hospital and Department of Primary Care and Population Sciences and Royal Free Centre for HIV Medicine, Royal Free \& University College Medical School.

\section{EDITORS' NOTICE}

\section{Inadvertent failure to disclose an} interest

Podophyllin office therapy against condyloma should be abandoned. Von Krogh et al (Sex Transm Inf 2001;77:409-12). The author Dr G Von Krogh inadvertently failed to disclose that he had received consultancy fees or reimbursement of expenses to attend educationa meetings relating to anogenital papillom virus infection from the following companies: $3 \mathrm{M}$, Perstorp, Stiefel, Oclassen, and MSD. In addition clinical trials on anogenital HPV infection had been funded within his department by both $3 \mathrm{M}$ and MSD. 